\title{
Association Between Reading Habit and Sleep Among Age Over 40 Years Community Residents: A Population-Based Evidence Study
}

\author{
Yong Zhang' \\ Yurun Du' \\ Shulan $\mathrm{He}^{\prime}$ \\ Xian Sun' \\ Jiafei Yang ${ }^{\prime}$ \\ Jiangping $\mathrm{Li}^{1,2}$
}

'Department of Epidemiology and Health Statistics, School of Public Health and Management, Ningxia Medical University, Yinchuan, Ningxia Hui Autonomous Region, 750004, People's Republic of China; ${ }^{2}$ Key Laboratory of Environmental Factors and Chronic Disease Control, Ningxia Medical University, Yinchuan, Ningxia Hui Autonomous Region, 750004, People's Republic of China
Correspondence: Jiangping $\mathrm{Li}$

Department of Epidemiology and Health Statistics, School of Public Health and

Management, Ningxia Medical University, Yinchuan, 750004, People's Republic of China

Tel +8609516980139

Email lijp@nxmu.edu.cn
Purpose: Sleep disturbance is a paramount public health concern that besets many modern middle-aged and elderly community residents. Reading is important to adults as it facilitates the completion of daily tasks, and might be associated with sleep issues. The present study aimed to analyze the association between reading and sleep using Chinese national survey data.

Patients and Methods: The 2018 China Family Panel Studies survey data were used, and the target sample was extracted according to age ( $>40$ years). Reading behavior and reading quantity were chosen as independent variables, and sleep duration, sleep-onset time, and sleep quality were selected as dependent variables. A multilevel mixed linear/ordinal logistic regression model was employed to evaluate the association, and restricted cubic splines with 4 knots were employed to flexibly model the association of reading quantity and sleep duration.

Results: A total of 18,740 adults were selected, and the reading rate was $15.04 \%$. Reading habit was significantly negatively associated with weekday sleep duration, but not with duration at weekends, as determined from the full set of confounders adjusted models. Reading behavior was also associated with delayed sleep-onset time (OR: 0.935, 95\% CI: 0.908-0.964), but not with sleep quality. Reading quantity showed a nonlinear relationship with sleep duration, appropriate reading quantity was related with long sleep duration.

Conclusion: Reading was associated with short sleep duration on weekdays, but not with sleep quality. Furthermore, reading was related to late sleep-onset time, and for the middleaged and elderly Chinese populations, appropriate reading quantity was related with long sleep duration.

Keywords: reading habit, sleep duration, sleep disturbance, sleep quality

\section{Introduction}

In recent years, sleep-related issues have increasingly caught the attention of the public. Individuals with sleep disorders may have numerous health problems and subsequent disorders, such as health-related quality of life, ${ }^{1}$ obesity, ${ }^{2}$ diabetes, ${ }^{3}$ cardiovascular and metabolic disorders, ${ }^{4}$ and even mental health. ${ }^{5}$ Sleep disorders in the elderly are a growing challenge around the world. ${ }^{6}$ China, the largest developing country in the world, has many people with a rapid aging time, poor sleep quality and inappropriate sleep duration, all of which are associated with a higher risk of mortality and lower odds of being in a healthy state in the elderly. ${ }^{7}$ Sleep problems have become an important factor affecting the quality of life and health in middle-aged and elderly people. 
In recent years, the negative influence on social interaction of urbanization in China has emerged in middle-aged and elderly populations who have experienced great changes in society, and life pressure is gradually increasing. ${ }^{8}$ Sleep deprivation among them has become more obvious, while an abundance of evidence shows that the use of electronic devices can reduce sleep quality among adolescents. ${ }^{9-12}$ The effect of printed reading materials seems to show a difference compared with e-book reading. ${ }^{13}$ Printed reading materials are still a preferred medium of reading for middleaged and elderly people due to their childhood environment (rarity of e-bookreading and lack of internet usage) and habitation. A previous study showed that reading nonmedical literature on a consistent basis may be associated with a significantly decreased likelihood of burnout in clinicians, ${ }^{14}$ which indirectly implies that reading might adjust individuals' mood and relieve undesirable emotions. Although an association between reading and mental health was determined, ${ }^{15}$ epidemiological evidence of sleep issues among middle and elderly individuals in China is lacking.

The present study aimed to explore the relationship between reading and sleep issues in middle-aged and elderly Chinese individuals using China Family Panel Studies (CFPS) 2018 survey wave data. It will intend to fill the gap in knowledge regarding printed materials reading behaviour and sleep in middle aged and elderly populations.

\section{Study Sample and Methods Data Source}

The data in this study were taken from the CFPS 2018 survey wave. The CFPS is an ongoing open longitudinal study on individual-, family-, and community-level information in contemporary China; the study was launched in 2010 by the Institute of Social Science Survey (ISSS) of Peking University, China. The studies focus on the economic, as well as the non-economic, wellbeing of the Chinese population, with a wealth of information covering such topics as economic activities, education outcomes, family dynamics and relationships, migration, and health. ${ }^{16}$ Detailed information about CFPS can be accessed at http://www.isss.pku.edu.cn/cfps/.

\section{Subset Sample}

The CFPS 2018 survey data set was selected due to sleep issues and reading items having been collected simultaneously. A total of 18,740 individuals were extracted in the present study according to age $>40$ years from 32,669 observations.

\section{Sleep-Related Variables}

Three items were used to evaluate the status of sleep: sleep duration (hours), sleep-onset time, and self-rated quality of sleep. Sleep duration includes average amount of sleep per day, weekdays sleep duration, and weekends sleep duration. In the original dataset, if participants reported their average amount of sleep, then the weekday and weekend sleep durations would be missing, and conversely, the average per day of sleep duration would be lacking. The following equation was used to calculate the amount of sleep (average per day):

$$
\text { Average sleep duration }=\frac{\begin{array}{l}
\text { weekday sleep duration } \times 5 \\
+ \text { weekend sleep duration } \times 2
\end{array}}{7}
$$

Sleep-onset time was categorized into three groups according to time of going to bed: early (earlier than 20:00 h), optimum (between 20:00 and 23:00 h), late (later than 23:00 h).

The quality of sleep was measured by subjective perception via the following question "I cannot sleep properly at night in the past week", corresponding options were: hardly any, < 1 day; sometimes, 1-2 days; often, 3-4 days; most of the time, 5-7 days.

\section{Reading Items}

Reading-related items comprised two parts. The first one is reading habit that was evaluated by the question "Have you ever read a book in the past 12 months, not for work or exams?", (1, yes; 5 , no). Reading quantity was measured by "How many books have you read in the past 12 months, excluding reading for work or exams?". In present study, we established a hypothesis that reading focuses on printed materials in middle-aged and elderly Chinese populations due to e-books not being popular among them.

\section{Covariates}

Demographic information such as age, sex, residential address (urban or rural), family size, marital status, and educational level were considered as confounding factors. The socioeconomic variables were life satisfaction (satisfaction), relative income level in local area (income status), social status in local area (social ladder); all above three questions were scored from 1 to 5 , with a higher score representing an advanced level. Lifestyle information 
included smoking habits (measured by the question "In the past months, have you smoked cigarettes?"), drinking status (estimated by "What was the frequency of alcohol consumption $>3$ times every week in the past month"), physical exercise (determined by the question "What was the frequency of physical exercise in the past week"), and nap habit (evaluated by a yes/no question, "Do you have a nap habit?"). Health-related variables were body mass index (BMI) [weight(kilograms)/height(meters) $\left.{ }^{2}\right]$, self-perceived health status (depicted by "How is your health in general?", with five options: excellent, very good, good, fair, and poor), unwell feeling (from the question "Did you feel unwell in the past 2 weeks?"), presence of chronic disease (extracted from the question "Have you had chronic diseases diagnosed by your doctor in the past half year?"), memorizing ability (assessed by the question "Can you remember the main things that happened to you in a week?", with five options: a little, a few, half, most, and all), and depression (tested by the question "Did you feel depressed in the past week?", with four options: $<1$ day, 1-2 days, 3-4 days, and 5-7 days).

\section{Statistical Strategy}

STATA MP Version 15.0 (STATA Corporation, College Station, TX, USA) was employed to analyze the data. The univariate analysis strategies were independent $t$-test, analysis of variance, Kruskal-Wallis rank test and $\chi^{2}$ test for quantitative and count variables, respectively. The association between reading and sleep issues was identified by multilevel mixed linear/ordinal logistic regression models. Several models were considered: Model 0 only included reading habit as explanatory variable; Model 1 was based on Model 0 and demographic information was added as independent variables; model 2 was based on Model 0 and included socioeconomic variables; Model 3 was based on Model 0 and included lifestyle-related variables; Model 4 included health-related variables and reading habits; Model 5 included all variables.

Education level as a potential confounding factor was considered in Model 1 and Model 5. We also employed restricted cubic spline with four knots to flexibly model the association of reading quantity and sleep duration. R 3.5.2 was used to create the figures.

\section{Results}

\section{Characteristics of the Participants}

Most of the participants' basic characteristics significantly differed in terms of reading habit, and similar results were also observed in the groups for sleep quality (Table S1). Reading rate in middle-aged and elderly Chinese of the current study is $15.04 \%$.

Table 1 shows that the average sleep duration and weekday sleep duration were significantly shorter in the reading group, sleep duration tended to decline with the frequency of poor sleep. The percentage of later sleeponset time was significantly higher in the reading group. A higher frequency of poor sleep quality was also observed in the non-reading group.

\section{Relationship Between Reading Quantity and Sleep Issues}

The average sleep duration and weekend sleep duration showed declining trends with reading quantity, which implied that more reading led to shorter sleep duration on weekends. In Figure 1, we used restricted cubic splines to flexibly model and visualize the relation of sleep duration and reading quantity. Overall, reading quantity showed deprivation characteristic for sleep duration, but proper reading per year (about 5 books) showed elevating trends and further when the reading number reached about 20 the trend turned to descending ( $P$ for non-linearity $<0.001)$. The similarity results were confirmed in the covariates adjusted figure (Figure 2).

Comparison results from Table 2 shows the distribution difference of reading quantity in terms of sleep-onset time, and sleep quality, and those with the highest reading quantity had the lowest frequency of poor sleep quality.

\section{Association Between Reading and Sleep Duration}

Table 3 shows that participants who did not have a reading habit were associated with long sleep duration in total average and weekend. However, an insignificant relationship was observed in weekend sleep duration and reading quantity.

\section{Sleep-Onset Time and Reading}

Table 4 shows the association between reading and sleep-onset time. Having no reading habit appears to be associated with earlier bedtime, which supports a $6.5 \%$ likelihood rate. This indicated that reading decreases sleep duration due to a later sleep onset, especially during weekdays. Reading quantity per year was positively correlated with sleep-onset time in the fully adjusted model, with statistical significance observed under the $10 \%$ level. 


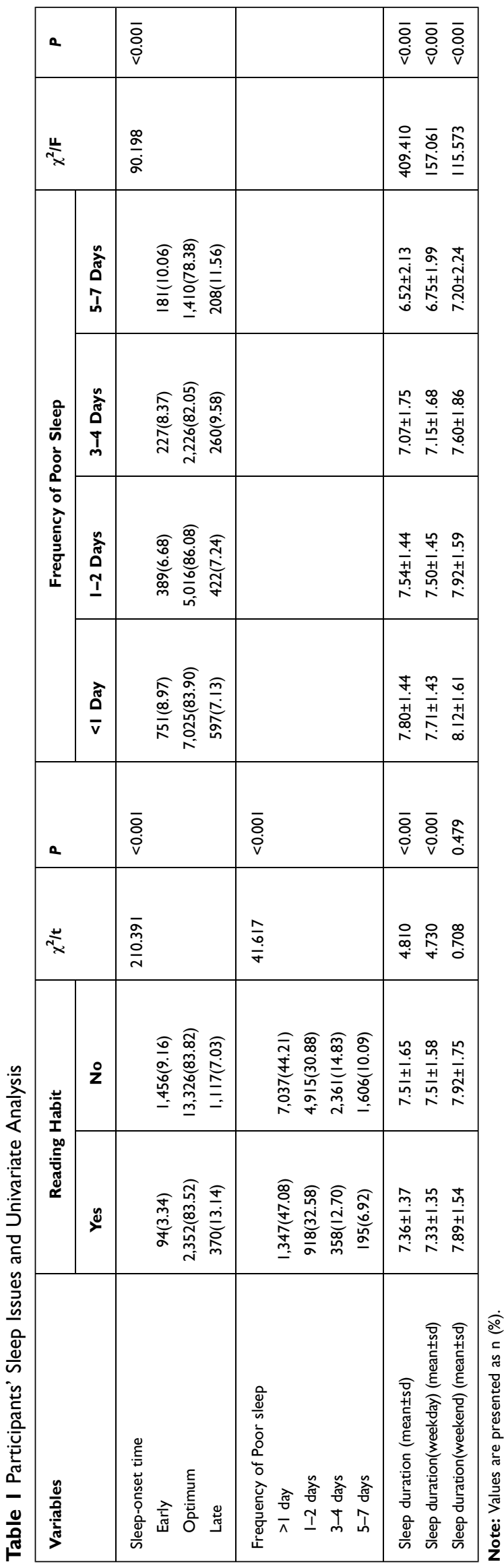

\section{Quality of Sleep and Reading Issues}

Although significant association between reading habit and sleep quality was observed in Model 0 , Model 2 and Model 3, insignificant association was found in all of the confounders adjusted models (Table 5). An association between reading quantity and sleep quality was not found in any model.

\section{Sensitivity Analysis}

The sensitivity analysis was performed using sleep issues that were answered, i.e., the subjects who only answered weekday and weekends sleep duration, against the remainder who answered regarding average sleep duration. Results are shown in Tables S2-S4, which are similar to our major finding. The robust features were displayed between reading and sleep.

\section{Discussions}

In the present study, we evaluated the association between reading and sleep issues among middle-aged and elderly Chinese populations using a national representative sample from the 2018 CFPS survey wave. Results showed that the reading rate in middle-aged and elderly populations was $15.04 \%$, which was lower than the rate in the 17th China National Reading Survey. ${ }^{17}$ The possible reason was that our target populations were middle-aged and elderly residents, who comprised a large portion of the Chinese population with illiteracy. Reading habit would be negatively related with sleep duration in total average and weekday sleep duration. A nonlinear association between reading quantity and sleep duration was observed, which showed a negative association, but appropriate reading quantity could be elevating it. Late sleep-onset time with reading habits was reported.

Reading for middle-aged and elderly individuals is a positive behavior because it facilitates the completion of daily tasks that are essential to independent living. ${ }^{18}$ In China, there were immense changes in the social structure and economic level in recent decades, and along with the development of urbanization, middle-aged and elderly residents are the main witnesses and affected population. ${ }^{19}$ Urbanization offers opportunities for improvements in health service provision, but the substantial health risks, including air pollution, occupational and traffic hazards, and the risks conferred by changing diets and activity need to be paid more attention. ${ }^{20}$ In this context, sleep issues seem to be a public concern due to 

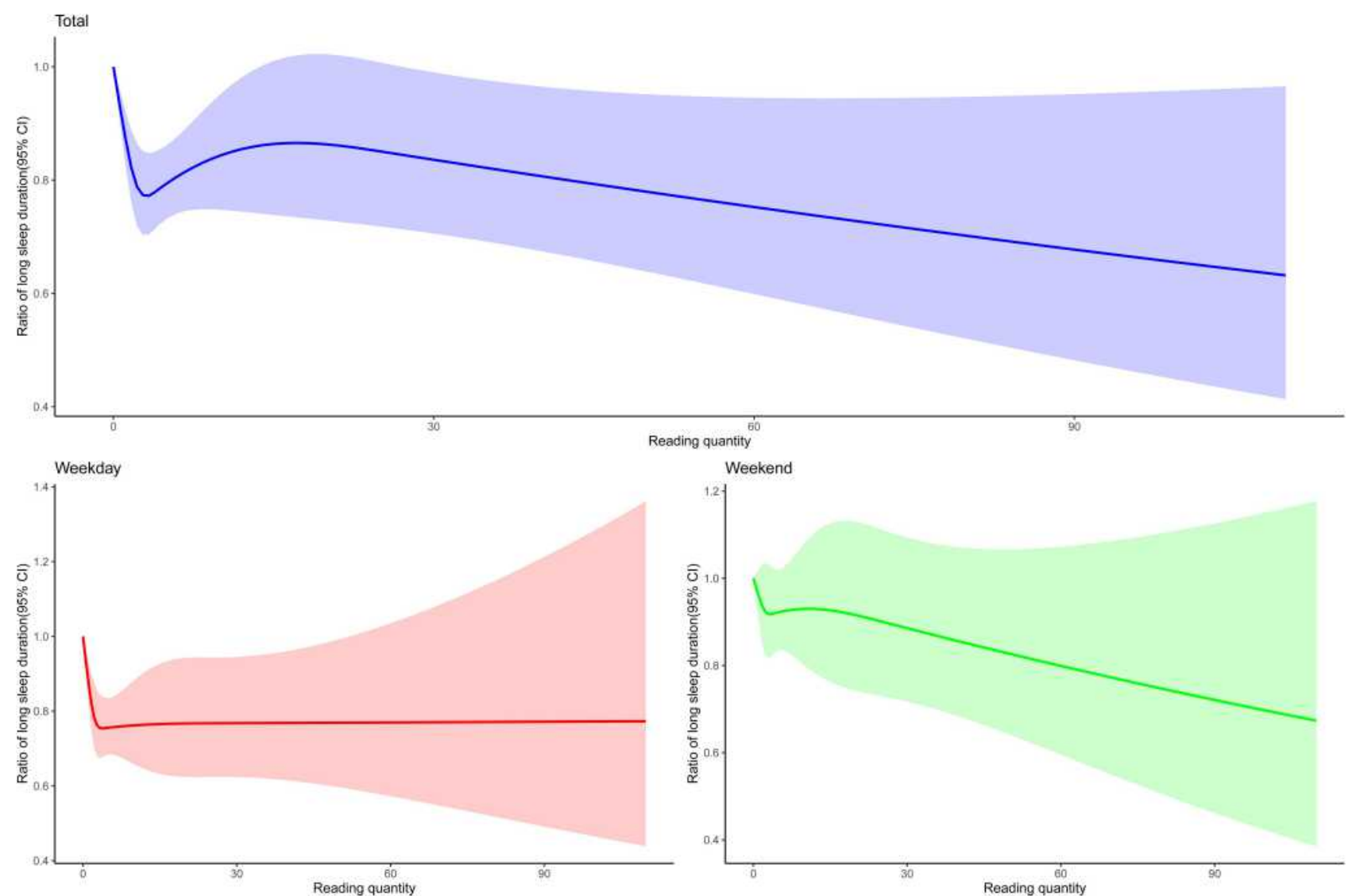

Figure I The level of sleep duration with reading quantity. Abbreviation: $\mathrm{Cl}$, confidence interval.

the development of society. Reading set as a potential factor that is related with sleeping was discussed by a previous study; ${ }^{21}$ our results showed that reading behavior associated negatively with sleep duration during weekdays among middle-aged and elderly Chinese residents, but not at weekends. Although a previous study found relevant valid evidence that reading can ameliorate declines in cognitive level in elderly people, ${ }^{22}$ sleep disturbance was not described. In the present study, the decreased weekday sleep duration attributed to reading might be due to reading time reducing the total bedtime on weekdays. Chronic sleep deprivation might be associated with negative influences on heatlh, such as immunity function lessening, heart trouble, cognitive impairment, etc. But our results showed appropriate reading could prolong sleep duration. In contrast, on weekends, participants might have had a lot of leisure time that can be devoted to reading. The above explanation appears to be a valid reason why reading delays sleep-onset time.

Although scientific evidence explaining how reading to adjust sleep quality is lacking, Melissa Ragsdale ${ }^{23}$ concluded that printed book reading can reduce stress, reading is an excellent part of a bedtime routine, and that reading before bed helps your body relax. But our results did not show an association between reading habit and sleep quality. The possible interpretation was that reading habit mostly benefits mental health; ${ }^{24}$ also, physical illness is accompanied by physical pain that might weaken the benefits to sleep. Meanwhile, a lower reading rate would offset the beneficial magnitude. And in future, prospective design studies need to verify this association. Reading might boost intelligence and help readers to release negative feelings. Nevertheless, reducing gloomy thoughts by reading during bedtime might provide a comfortable condition for falling asleep. Furthermore, although reading habit was associated with short sleep duration, sleep quality was not influenced. This might further corroborate the previous statement that reading can provide a relaxed start of sleep. Hence, sleep scientists should further explore these relationships and determine if it can be applied in clinical treatment. 

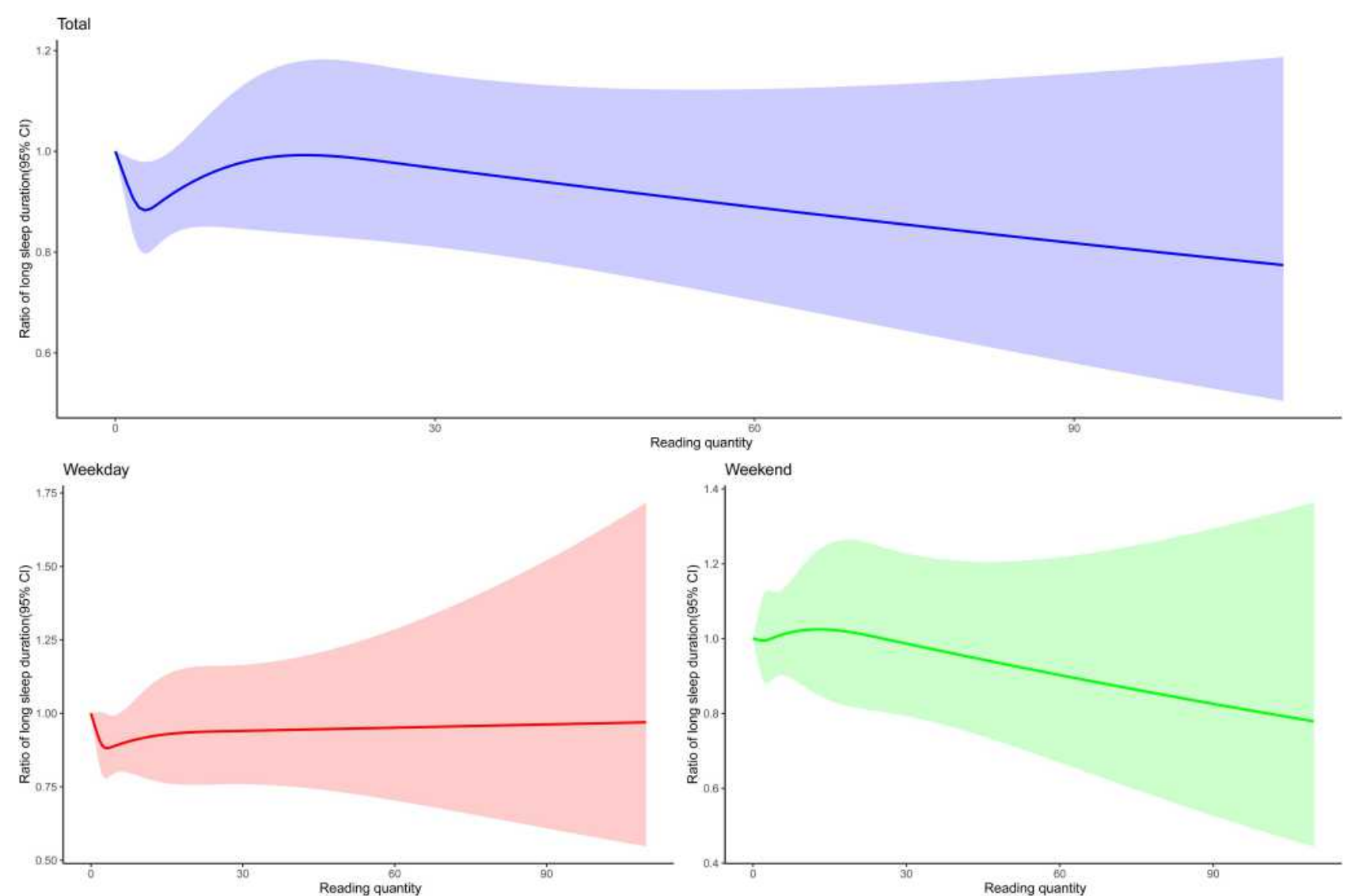

Figure $\mathbf{2}$ The level of sleep duration with reading quantity after controlling for covariates. Abbreviation: $\mathrm{Cl}$, confidence interval.

This study has some limitations that require more attention. First, although the sample was from a national survey, most of the information was collected via a questionnaire, which has possible recall bias. Second, the cross-sectional study design prevents causal deduction,

Table 2 Description and Comparison Between Reading Quantity and Sleep Onset Time, Sleep Quality

\begin{tabular}{|l|c|c|c|c|}
\hline Variables & \multicolumn{2}{|c|}{$\begin{array}{c}\text { Number of Books } \\
\text { Read per Year }\end{array}$} & \multirow{2}{*}{$\chi^{2}$} & \\
\cline { 2 - 3 } & Mean & $\begin{array}{c}\text { Standard } \\
\text { Deviation }\end{array}$ & & \\
\hline Sleep Onset time & 5.87 & 7.87 & & \\
Earlier & 6.02 & 15.25 & & \\
Optimum & 8.89 & 23.68 & & \\
Lately & & & \multirow{2}{*}{19.510} & \multirow{2}{*}{0.0003} \\
\hline Frequency of Poor sleep & 7.13 & 18.60 & & \\
Less than one day & 5.15 & 13.94 & & \\
I-2 days & 6.74 & 13.93 & & \\
3-4 days & 6.49 & 15.42 & & \\
5-7 days & & & & \\
\hline
\end{tabular}

which limits association. Third, regarding the reading materials, we established the assumption that the target populations prefer printed books, thus ignoring the influence of reading behavior using electronic books. The impact might offset the role of printed book reading that showed a positive effect on sleep. Fourth, although many potential confounding factors were considered, some important variables were not included, such as classifications of reading. Finally, there were no mentions of the time of day that the volunteers read, which might be a key factor affecting sleep directly. A future study might establish a stricter design and remedy the mentioned shortcomings among a specific population.

\section{Conclusions}

Although reading was associated with short sleep duration on weekdays, it did not associate with sleep quality. Furthermore, reading habit was related to late sleep-onset time, but not with sleep quality. For the middle-aged and elderly Chinese populations, appropriate reading quantity related with long sleep duration. 
Table 3 Association Between Reading and Sleep Duration in Middle-Aged and Elderly Populations

\begin{tabular}{|c|c|c|c|c|c|c|}
\hline \multirow[t]{2}{*}{ Models } & \multicolumn{3}{|c|}{ No Reading Habit } & \multicolumn{3}{|c|}{ Reading Quantity } \\
\hline & Beta & $95 \% \mathrm{Cl}$ & $P$ & Beta & $95 \% \mathrm{Cl}$ & $P$ \\
\hline \multicolumn{7}{|c|}{ Sleep Duration } \\
\hline Model 0 & 0.022 & $0.006-0.038$ & 0.007 & -0.001 & $-0.005-0.002$ & 0.346 \\
\hline Model I & 0.016 & $-0.00 \mathrm{I}-0.034$ & 0.059 & -0.001 & $-0.004-0.002$ & 0.408 \\
\hline Model 2 & 0.021 & $0.005-0.037$ & 0.010 & -0.001 & $-0.005-0.002$ & 0.346 \\
\hline Model 3 & 0.026 & $0.010-0.042$ & 0.002 & -0.001 & $-0.005-0.002$ & 0.350 \\
\hline Model 4 & 0.026 & $0.010-0.042$ & 0.002 & -0.001 & $-0.004-0.002$ & 0.473 \\
\hline Model 5 & 0.020 & $0.003-0.037$ & 0.024 & -0.001 & $-0.004-0.002$ & 0.588 \\
\hline \multicolumn{7}{|c|}{ Sleep Duration(weekdays) } \\
\hline Model 0 & 0.03 & $0.012-0.048$ & 0.001 & 0.001 & $-0.004-0.005$ & 0.763 \\
\hline Model I & 0.019 & $0.000-0.039$ & 0.052 & 0.002 & $-0.003-0.006$ & 0.454 \\
\hline Model 2 & 0.027 & $0.009-0.046$ & 0.003 & 0.001 & $-0.004-0.005$ & 0.757 \\
\hline Model 3 & 0.034 & $0.015-0.052$ & $<0.001$ & 0.001 & $-0.003-0.005$ & 0.707 \\
\hline Model 4 & 0.030 & $0.012-0.049$ & 0.001 & 0.001 & $-0.004-0.005$ & 0.765 \\
\hline Model 5 & 0.021 & $0.002-0.041$ & 0.033 & 0.002 & $-0.003-0.006$ & 0.444 \\
\hline \multicolumn{7}{|c|}{ Sleep Duration(weekends) } \\
\hline Model 0 & -0.005 & $-0.025-0.015$ & 0.644 & -0.002 & $-0.007-0.003$ & 0.360 \\
\hline Model I & -0.002 & $-0.024-0.020$ & 0.839 & -0.002 & $-0.007-0.003$ & 0.447 \\
\hline Model 2 & -0.006 & $-0.026-0.015$ & 0.59 & -0.002 & $-0.007-0.003$ & 0.343 \\
\hline Model 3 & 0.000 & $-0.021-0.020$ & 0.974 & -0.002 & $-0.007-0.003$ & 0.434 \\
\hline Model 4 & -0.003 & $-0.024-0.017$ & 0.753 & -0.002 & $-0.007-0.003$ & 0.446 \\
\hline Model 5 & 0.001 & $-0.021-0.022$ & 0.962 & -0.001 & $-0.006-0.003$ & 0.561 \\
\hline
\end{tabular}

Notes: Model 0 only included reading habit as explanatory variable; Model I was based on Model 0 and included demographic information as independent variables; Model 2 was based on Model 0 and included socioeconomic variables; Model 3 was based on Model 0 and included lifestyle-related variables; Model 4 included health-related variables and reading habits; Model 5 included all variables.

Abbreviation: $\mathrm{Cl}$, confidence interval.

Table 4 Association Between Reading Habit and Sleep-Onset Time in Middle-Aged and Elderly Populations

\begin{tabular}{|l|c|c|c|c|c|c|}
\hline \multirow{2}{*}{ Models } & \multicolumn{3}{|c|}{ No Reading Habit } & \multicolumn{3}{c|}{ Reading Quantity } \\
\cline { 2 - 7 } & OR & $\mathbf{9 5 \%}$ Cl & P & OR & $95 \%$ CI & P \\
\hline Model 0 & 0.824 & $0.802-0.846$ & $<0.001$ & 1.009 & $1.002-1.016$ & 0.012 \\
Model I & 0.929 & $0.901-0.956$ & $<0.001$ & 1.007 & $0.999-1.014$ & 0.071 \\
Model 2 & 0.828 & $0.805-0.851$ & $<0.001$ & 1.009 & $1.002-1.016$ & 0.015 \\
Model 3 & 0.825 & $0.803-0.848$ & $<0.001$ & 1.009 & $1.001-1.016$ & 0.018 \\
Model 4 & 0.849 & $0.825-0.873$ & $<0.001$ & 1.009 & $1.002-1.016$ & 0.017 \\
Model 5 & 0.935 & $0.908-0.964$ & $<0.001$ & 1.006 & $0.999-1.014$ & 0.087 \\
\hline
\end{tabular}

Notes: Model 0 only included reading habit as explanatory variable; Model I was based on Model 0 and included demographic information as independent variables; Model 2 was based on Model 0 and included socioeconomic variables; Model 3 was based on Model 0 and included lifestyle-related variables; Model 4 included health-related variables and reading habits; Model 5 included all variables.

Abbreviations: $\mathrm{Cl}$, confidence interval; OR, odds ratio. 
Table 5 Association Between Reading and Sleep Quality in Middle-Aged and Elderly Populations

\begin{tabular}{|l|c|c|c|c|c|c|}
\hline \multirow{2}{*}{ Models } & \multicolumn{3}{|c|}{ No Reading Habit } & \multicolumn{3}{c|}{ Reading Quantity } \\
\cline { 2 - 7 } & OR & $\mathbf{9 5 \%}$ Cl & $\mathbf{P}$ & $\mathbf{O R}$ & $\mathbf{9 5 \%} \mathbf{C l}$ & $\mathbf{P}$ \\
\hline Model 0 & 1.052 & $1.032-1.072$ & $<0.001$ & 0.996 & $0.991-1.001$ & 0.128 \\
Model I & 0.994 & $0.974-1.015$ & 0.591 & 0.997 & $0.992-1.002$ & 0.207 \\
Model 2 & 1.056 & $1.037-1.077$ & $<0.001$ & 0.996 & $0.991-1.001$ & 0.110 \\
Model 3 & 1.044 & $1.024-1.064$ & $<0.001$ & 0.997 & $0.992-1.001$ & 0.171 \\
Model 4 & 1.009 & $0.990-1.029$ & 0.360 & 0.996 & $0.991-1.001$ & 0.106 \\
Model 5 & 0.992 & $0.97 I-1.013$ & 0.460 & 0.996 & $0.991-1.001$ & 0.100 \\
\hline
\end{tabular}

Notes: Model 0 only included reading habit as explanatory variable; Model I was based on Model 0 and included demographic information as independent variables; Model 2 was based on Model 0 and included socioeconomic variables; Model 3 was based on Model 0 and included lifestyle-related variables; Model 4 included health-related variables and reading habits; Model 5 included all variables.

Abbreviations: $\mathrm{Cl}$, confidence interval; $\mathrm{OR}$, odds ratio.

\section{Abbreviations}

CFPS, China Family Panel Studies; CI, confidence interval; $\mathrm{OR}$, odds ratio; SD, standard deviation.

\section{Acknowledgment}

The authors sincerely thank the consent of data access from China Family Panel Studies (CFPS), funded by 985 Program of Peking University and carried out by the Institute of Social Science Survey of Peking University. The authors are grateful to Zeshun Jiang for facilitating the drawing of the revised figures, and Rui Zhang for her valuable advice in the revised manuscript.

\section{Funding}

The authors disclose receipt of the following financial support for the research, authorship, and/or publication of this article: This work was supported by Excellent junior scholar Program funded by the Department of Education of Ningxia (NGY2017087), and the 2019 Ningxia Medical University Dominant Discipline Group Construction Project.

\section{Disclosure}

The authors declared no potential conflicts of interest with respect to the research, authorship, and/or publication of this article.

\section{References}

1. Darchia N, Oniani N, Sakhelashvili I, et al. Relationship between sleep disorders and health related quality of life - results from the Georgia SOMNUS study. Int J Environ Res Public Health. 2018;15(8):1588. doi:10.3390/ijerph15081588
2. Gandolphi LRC, Okazaki KM, Nozoe KT, Polesel DN, Andersen ML, Tufik S. Influence of sleep disorders on television viewing time, diabetes and obesity. Diabetic Med. 2015;32 (1):141-142. doi:10.1111/dme.12603

3. Nieto J, Surani S, Huerta-Alardín AL, et al. Sleep-related disorders, diabetes and obesity: understanding the facts. Curr Respir Med Rev. 2006;2(3):325-329. doi:10.2174/157339806778019006

4. Grandner MA, Jackson NJ, Pak VM, Gehrman PR. Sleep disturbance is associated with cardiovascular and metabolic disorders. J Sleep Res. 2012;21(4):427-433. doi:10.1111/j.1365-2869.2011.00990.x

5. Winokur A, Kamath J. Sleep disorders and mental health. Psychiat Clin N Am. 2015;38(4):xiii-xiv. doi:10.1016/j.psc.2015.08.003

6. Gulia KK, Kumar VM. Sleep disorders in the elderly: a growing challenge. Psychogeriatrics. 2018;18(3):155-165. doi:10.1111/ psyg. 12319

7. Qiu L, Sautter J, Liu Y, Gu D. Age and gender differences in linkages of sleep with subsequent mortality and health among very old Chinese. Sleep Med. 2011;12(10):1008-1017. doi:10.1016/j. sleep.2011.04.014

8. Li X, Song J, Lin T, Dixon J, Zhang G, Ye H. Urbanization and health in China, thinking at the national, local and individual levels. Environ Health-Glob. 2016;15(S1):S32. doi:10.1186/s12940-0160104-5

9. Gronli J, Byrkjedal IK, Bjorvatn BR, et al. Reading from an iPad or from a book in bed: the impact on human sleep. a randomized controlled crossover trial. Sleep Med. 2016;21(21):86-92. doi:10.1016/j.sleep.2016.02.006

10. Taylor AW, Winefield H, Kettler L, Roberts R, Gill TK. A population study of 5 to 15 year olds: full time maternal employment not associated with high BMI. The importance of screen-based activity, reading for pleasure and sleep duration in children's BMI. Matern Child Health J. 2012;16(3):587-599. doi:10.1007/s10995-011-0792-y

11. Hysing M, Pallesen S, Stormark KM, Jakobsen R, Lundervold AJ, Sivertsen B. Sleep and use of electronic devices in adolescence: results from a large population-based study. BMJ Open. 2015;5(1): e6748. doi:10.1136/bmjopen-2014-006748

12. Cain N, Gradisar M. Electronic media use and sleep in school-aged children and adolescents: a review. Sleep Med. 2010;11(8):735-742. doi:10.1016/j.sleep.2010.02.006

13. Sleep CS. Is reading before bed a good idea? Does reading help you sleep? 2017. Available from: https://uk.tempur.com/blog/readingbefore-bed-good-idea.html. Accessed December 21, 2020.

14. Marchalik D, Rodriguez A, Namath A, et al. The impact of non-medical reading on clinician burnout: a national survey of palliative care providers. Ann Palliat Med. 2019;8(4):428-435. doi:10.21037/apm.2019.05.02 
15. Gallucci M, Mazzuco S, Ongaro F, et al. Body mass index, lifestyles, physical performance and cognitive decline: the "Treviso Longeva (TRELONG)" study. J Nutr Health Aging. 2013;17(4):378-384. doi:10.1007/s12603-012-0397-1

16. Xie Y, Lu P. The sampling design of the China Family Panel Studies (CFPS). Chin J Sociol. 2015;1(4):471-484. doi:10.1177/ 2057150X15614535

17. Daily CY. The 17th National Reading Survey: the average number of printed books read by adults in 2019 is $4.65 ; 2020$. Available from: http://news.cyol.com/app/2020-04/20/content_18577163.htm. Accessed August 9, 2020.

18. Gordon PC, Lowder MW, Hoedemaker RS. Cognition, Language and Aging. John Benjamins Publishing Company: Amsterdam; 2016.

19. Song C, Liu Q, Gu S, Wang Q. The impact of China's urbanization on economic growth and pollutant emissions: an empirical study based on input-output analysis. J Clean Prod. 2018;198:1289-1301. doi:10.1016/j.jclepro.2018.07.058

20. Gong P, Liang S, Carlton EJ, et al. Urbanisation and health in China. Lancet. 2012;379(9818):843-852. doi:10.1016/S0140-6736(11) 61878-3
21. Exelmans L, Van den Bulck J. Bedtime mobile phone use and sleep in adults. Soc Sci Med. 2016;148(1):93-101. doi:10.1016/j. socscimed.2015.11.037

22. Sörman DE, Ljungberg JK, Rönnlund M. Reading habits among older adults in relation to level and 15-year changes in verbal fluency and episodic recall. Front Psychol. 2018;9:1872. doi:10.3389/ fpsyg.2018.01872

23. Ragsdale M. 5 ways reading before bed can help you sleep better at night. 2017. Available from: https://www.bustle.com/p/5-waysreading-before-bed-can-help-you-sleep-better-at-night-2742107. Accessed August 9, 2020.

24. Wilson RS, Boyle PA, Yu L, Barnes LL, Schneider JA, Bennett DA. Life-span cognitive activity, neuropathologic burden, and cognitive aging. Neurology. 2013;81(4):314-321. doi:10.1212/WNL.0b013e31 $829 \mathrm{c} 5 \mathrm{e} 8 \mathrm{a}$

\section{Publish your work in this journal}

Nature and Science of Sleep is an international, peer-reviewed, open access journal covering all aspects of sleep science and sleep medicine, including the neurophysiology and functions of sleep, the genetics of sleep, sleep and society, biological rhythms, dreaming, sleep disorders and therapy, and strategies to optimize healthy sleep.
The manuscript management system is completely online and includes a very quick and fair peer-review system, which is all easy to use. Visit http://www.dovepress.com/testimonials.php to read real quotes from published authors. 